\title{
ARQUEOLOGIA, PATRIMÔNIO E SOCIEDADE: QUEM DEFINE A AGENDA?
}

\author{
Lucas de Melo Reis Bueno*
}

Resumo: O objetivo deste texto é contribuir para uma discussão que tem crescido e ocupado um espaço cada vez mais importante no âmbito da Arqueologia Brasileira nos últimos anos: o papel da arqueologia e dos arqueólogos na formulação de políticas de gestão do patrimônio. Para discutir essa questão apresentaremos uma história da arqueologia no Brasil, destacando alguns momentos crucias desta trajetória, marcados por formulações jurídicas a respeito da conceituação de Patrimônio e sua influência na prática arqueológica. Como veremos, apesar de haver uma ligação estreita entre o ingresso da arqueologia na academia e modificações na formulação de leis sobre patrimônio, os arqueólogos se esquivaram por muito tempo de tomar à frente nessa discussão.

Palavras-chave: Arqueologia. Patrimônio. Academia. Educação.

\begin{abstract}
This paper intends to add some points in a discussion that has increased and it's calling more attention in Brazilian archaeology since a couple of years: the hole of archaeology and archaeologists in defining ways for political heritage management. To discuss this question we'll present a history of Brazilian archaeology, highlighting some crucial moments of this trajectory, that were marked by juridical formulations about the heritage concept and its influence in archaeological practice. As we'll see, despite the existence of a close connection between the entrance of archaeology in the academy and important modifications in the heritage laws, the archaeologists were, for a long time, away of the decision making process about this issue.
\end{abstract}

Keywords: Archaeology. Heritage. Academy. Education.

\footnotetext{
* Universidade Federal de Santa Catarina (UFSC). E-mail: lucasreisbueno@gmail.com
} 


\section{INTRODUÇÃO}

O objetivo deste texto é contribuir para uma discussão que tem crescido e ocupado um espaço cada vez mais importante no âmbito da Arqueologia Brasileira nos últimos anos: o papel da arqueologia e dos arqueólogos na formulação de políticas de gestão do patrimônio. O impulso para essa discussão se sustenta numa perspectiva que concebe a arqueologia definitivamente como uma ciência social, pois envolve a construção de um discurso sobre o passado elaborado no presente por sujeitos inseridos em contextos históricos definidos que acarretam compromissos sociais, políticos, culturais. ${ }^{1}$

Essa postura ou essa perspectiva independe do tema, da região, do período com o qual se está trabalhando uma vez que o que a Arqueologia constrói são discursos sobre e para as pessoas do presente. Assim, não há alternativa para a Arqueologia - todo discurso envolve uma relação de poder e se posicionar é inevitável. ${ }^{2}$

Para discutir essa questão apresentaremos uma história da arqueologia no Brasil, destacando alguns momentos crucias desta trajetória, marcados por formulações jurídicas a respeito da conceituação de Patrimônio e sua influência na prática arqueológica. Seguindo essa proposta, pretendemos enfatizar a íntima relação existente entre o processo de consolidação da Arqueologia enquanto disciplina científica e acadêmica e as discussões e conceituações do que é Patrimônio Arqueológico em termos jurídicos. Como veremos, apesar de haver uma ligação estreita entre o ingresso da arqueologia na academia e modificações na formulação de leis sobre patrimônio, os arqueólogos se esquivaram por muito tempo de tomar à frente nessa discussão.

\section{ARQUEOLOGIA, SPHAN E O ESTADO NOVO}

AArqueologia, entendida enquanto discurso construído a partir de fontes materiais, remonta, no Brasil, ao início do século XIX. ${ }^{3}$ Com papel importante nas discussões sobre construção de uma ideia de nação, a arqueologia realizada durante o Império e a República procura gerar subsídios para elabração de discursos a respeito da origem e organização social dos grupos indígenas. ${ }^{4}$ Com a criação, ao longo do Império e da República, de Museus Etnográficos há uma incorporação do conhecimento arqueológico por essas instituições que passam a ser os principais locais de produção e disseminação do conhecimento arqueológico na sociedade nacional. ${ }^{5}$ Durante esse período a Arqueologia brasileira vivencia uma intensa produtividade, com inúmeros artigos e trabalhos publicados em âmbito nacional e internacional. 
A partir de 1920, com o declinio do papel dos Museus enquanto principais centros de produção do conhecimento, há uma diminuição sensível na atuação frenética que marcou a produção da ciência no Brasil durante a virada do século XIX para o XX. ${ }^{6}$ De uma forma geral o interesse pelo estudo sobre o passado, a origem dos grupos nativos diminui e há um incrementeo na tentativa de construir uma nova imagem da nação, moderna, industrial, urbana, para o quê outros grupos sociais desempenham papel preponderante. ${ }^{7}$

Esse momento de saída da Arqueologia dos Museus evidencia um certo distanciamento entre arqueologia e antropologia, que até então caminhavam juntas, decorrente tanto de questões institucionais quanto teoricas, envolvendo uma crítica aos pressupostos evolucionistas e positivistas que marcaram o período anterior. ${ }^{8}$ A arqueologia, presa a um certo cientificismo, herança da institucionalização da disciplina vinculada aos Museus, passa por um período marcado principalmente pela divulgação do conhecimento já produzido, pela elaboração de sínteses e popularização dos trabalhos realizados nos anos anteriores. $^{9}$

Ao sair dos museus a produção do conhecimento arqueológico se pulveriza nos Institutos Históricos e Geográficos regionais e em sociedades formadas por intelectuais pertencentes à elites locais. Nesse período muitos médicos, advogados, engenheiros que fazem parte desse movimento de valorização do conhecimento intelectual assumem o papel de não só produzir sínteses com base no que havia sido publicado durante a era dos museus, mas também de realizar pesquisas, escavações e formar coleções. ${ }^{10}$

Assim, entre a era dos museus e o ingresso da arqueologia nas universidades temos um período, denominado por alguns autores, como "era dos amadores". ${ }^{11}$ Embora este seja um termo um tanto quanto pejorativo, ele cabe bem na história da institucionalização da arqueologia no Brasil, pois esta, ao ingressar nas universidades nos anos 50 e 60, procurará se afirmar através de um discurso de exclusão, opondo-se ao que vinha sendo feito nas décadas anteriores principalmente em termos de método. ${ }^{12}$

Embora seja senso comum dentre as histórias da arqueologia brasileira caracterizar este período entre guerras como um período de fraca produção intelectual, temos, na verdade, uma produção intensa e, principalmente, uma ampla disseminação do conhecimento arqueológico, atingindo diversos veículos de divulgação, seja através de obras literárias ou jornais. ${ }^{13}$

Apesar da Arqueologia passar nesse período por um certo vácuo institucional - sai dos museus mas ainda não é incorporada de fato pelas universidades que estão se estruturando - este é, contraditoriamente, um período de construção jurídica-institucional da nação. No que se refere à Educação e Ciência, ao longo da década de 1930 há a criação da Universidade de São Paulo (1934), da Universidade do Brasil (futura UFRJ-1937), a criação do 
Ministério de Educação e Saúde (1931) e do Departamento de Imprensa e Propaganda, além da inclusão da história do Brasil como disciplina autônoma nos currículos escolares. ${ }^{14}$

É dentro desse processo que podemos entender também a criação da Secretaria do Patrimônio Histórico e Artístico Nacional, sob direção de Rodrigo de Mello Franco Andrade e a primeira lei de proteção ao patrimônio, a qual surge em 1937, sendo formulada por Mário de Andrade e promulgada enquanto decreto-lei. ${ }^{15}$

Com relação à conceituação de Patrimônio a lei estabelece que "constitui o patrimônio histórico e artístico nacional o conjunto dos bens móveis e imóveis existentes no país e cuja conservação seja de interesse público, quer por sua vinculação a fatos memoráveis da história do Brasil, quer por seu excepcional valor arqueológico ou etnográfico, bibliográfico ou artístico.” No entanto a sua oficialização deve necessariamente passar pelo processo de tombamento "os bens a que se refere o presente artigo só serão considerados parte integrante do patrimônio histórico e artístico nacional depois de inscritos separada ou conjuntamente num dos quatro livros de tombo". ${ }^{16}$

Devido ao teor da lei cabe-nos a pergunta: o que são fatos memoráveis, o que é excepcional valor arqueológico?

Na prática essa lei foi direcionada quase exclusivamente à sítios históricos, igrejas, fortalezas e construções arquitetônicas vinculadas a uma visão específica da História do Brasil, equiparada à História colonial e à influência europeia na constituição da sociedade brasileira. ${ }^{17}$

Outro aspecto importante derivado do conteúdo dessa lei é o fato de se estabelecer uma relação próxima entre arqueologia e história que, ao privilegiar os bens arquitetônicos, aproxima também a arquitetura - cria-se uma ligação entre arqueologia-história e arquitetura que, somada ao distanciamento teórico da antropologia que já vinha ocorrendo desde 1920, acaba por ser responsável por causar uma separação entre essas disciplinas no Brasil. Nesse caso, a arqueologia vai se identificar muito mais com uma história factual, descritiva, que se preocupa em agrupar fatos e datas do que em discutir a formação do povo brasileiro.

Ao enfatizar a necessidade de tombamento para preservação dos bens arqueológicos essa lei se torna praticamente inócua - primeiro devido à extrema dificuldade de implementação do processo de tomabmento e, em segundo, por ser absolutamente pardoxal, pois no momento em que o bem fosse tombado ele deveria ser preservado sem maiores modificações o que impedia a realização das próprias pesquisas arqueológicas. ${ }^{18}$

Isso faz com que vários pesquisadores interessados no tema continuem enfatizando a necessidade de discussão e aprimoramento da legislação referente à proteção do patrimônio arqueológico, com ênfase principalmente nos sítios 
pré-históricos, dentre os quais se destacavam, até o momento, os sambaquis. Esta discussão se intensifica nas décadas de 1940 e 1950, assumindo um papel de destaque nas recêm criadas Universidades. ${ }^{19}$

\section{ARQUEOLOGIA E ACADEMIA: UMA DEMANDA PRESERVACIONSITA}

$\mathrm{Na}$ esteira dessa preocupação e embate entre as forças econômicas e os intelectuais orientados pela necessidade de preservação do patrimônio arqueológico uma série de iniciativas começam a aparecer no Rio de Janeiro, em São Paulo e no Paraná, encabeçadas principalmente por três intelectuais: Luis de Castro Faria, Paulo Duarte e José Loureiro Fernandes. São esses três personagens que serão ao mesmo tempo responsáveis pela formulação da lei federal de 1961 e também os responsáveis pelo ingresso da arqueologia nas universidades, apontando para a importância do movimento preservacionista no processo de academicização da arqueologia. ${ }^{20}$

Apesar desses esforços, durante as décadas de 1930, 1940, 1950, pouco de fato se conseguiu prevenir a destruição do patrimônio arqueológico, em especial dos sambaquis, utilizados como matéria prima para produção do cal necessário para garantir o crescimento urbano das grandes cidades que se formavam, principalmente na região sudeste/sul do país. ${ }^{21}$

A primeira conquista concreta para começar a reverter essa situação foi obtida no Paraná em 1951. Através do esforço pessoal de Jose Loureiro Fernandes o governador do estado através do decreto 1.346 de 30 de maio de 1951, reservou para fins de pesquisa proto-histórica os sambaquis existentes no litoral paranaense. ${ }^{22}$

No ano seguinte, 1952, com o apoio de Paul Rivet, Paulo Duarte consegue articular forças para criar a Comissão de Pré-história instituída por decreto do governo paulista e subordinada diretamente ao governador destinada à proteção dos interesse científico dos sambaquis, grutas e lapas situadas em território nacional. ${ }^{23}$

Na mesma esteira preservacionista e dando continuidade às atividades de Loureiro Fernades no Paraná, em 1954 é fundado o Centro de Pesquisas Arqueológicas junto à Universidade Federal do Paraná. Com isso, em meados da década de 1950 o Paraná contava já com o CEPA, com o Museu Paranaense e com o Instituto de Biologia e Pesquisas Tecnológicas, coordenado então por João Jose Bigarella. ${ }^{24}$

No Rio de Janeiro encontramos na década de 1950 uma situação bastante peculiar - há uma multiplicação de instituições privadas orientadas para o estudo da arqueologia: Associação Brasileira de Pesquisas Arqueológicas 
em 1958, Instituto de Arqueologia Brasileira em 1961, Centro Brasileiro de Arqueologia, também em 1961. ${ }^{25}$

Essa efervescência em torno da questão da preservação dos sítios arqueológicos levou a criação de uma comissão, instituída por Juscelino Kubitschek, integrada pelos diretores do Departemanto Nacional de Produção Mineral, do SPHAN, da Comissão de Pré-história de SP, do CEPA, e do Museu Nacional, a qual redigiu um projeto de lei encaminhado ao congresso em $1957 .{ }^{26}$ Esse projeto só foi enviado ao senado em 1960, sendo sancionado por Janio Quadros em 1961. A lei 3.924 de 26 de julho de 1961 altera significativamente o conceito de Patrimônio e apresenta uma série de aspectos específicos e fundamentais para garantia de sua preservação. Dentre a abrangência de aspectos contemplados por essa Lei, cabe mencionar os seguintes pontos: ${ }^{27}$

os monumentos arqueológicos pré-históricos de qualquer natureza existentes no território nacional e todos os elementos que nele se encontram ficam sob guarda e proteção do poder público (...) a propriedade da superfície regida pelo direito comum não inclui a das jazidas arqueológicas ou pré-históricas, nam a dos objetos nela encontrados (...) as jazidas arqueológicas ou pré-históricas de qualquer natureza são consideradas para todos os efeitos bens da união (...) proibido em todo o território nacional o aproveitamento econômico, a destruição ou a mutilação, para qualquer fim, dos monumentos arqueológicos ou préhistóricos antes de serem devidamente pesquisados.

A amplitude dessa lei, a qual vigora até os dias de hoje, muda completamente a situação do patrimônio arqueológico e sua preservação. A partir desse momento, com o respaldo legal para garantia da preservação do patrimônio um novo problema prático se coloca para aqueles que vinham lutando pela sua aprovação: Quem vai garantir o cumprimento da lei?

Surge, para isso uma necessidade bem concreta: formar pessoal capacitado para localizar, registrar, catalogar o registro arqueológico de todo o País, tendo em vista o risco eminente de destruição do patrimônio. ${ }^{28}$

É nesse contexto, para dar conta dessa demanada que a Arqueologia ingressa na academia. Não há um projeto acadêmico específico para a arqueologia, ao contrário do que ocorria nas demais ciências sociais. São demandas preservacionistas, decorrentes da constatação de uma intensificação no processo de desmonte, de descaracaterização do patrminoio arqueológico que orientam essa formação. Se o objetivo era preservar era preciso identificar, caracterizar, catalogar os sítios. ${ }^{29}$ 
A fim de viabilizar essa formação, Jose Loureiro Fernandes articula o convite para participação de pesquisadores estrangeiros - era precisa formar arqueólogos no país que pudessem ocupar os espaços abertos nas universidades e que viabilizassem não só a aprovação das leis de proteção ao patrimônio, mas que conseguissem fazer com que elas fossem aplicadas. ${ }^{30}$

Cria-se uma situação paradoxal nesse momento - se durante o Imperio e a Republica a arqueologia e a etnologia andavam entrelaçadas, agora a arqueologia, ligada à história, distanciava-se da antropologia sendo que seu objeto de estudo era justamente o passado das sociedades indígenas.

Diferentes fatores contribuiram para essa situação. O caráter cientificista, orientado para coletar, descrever e classificar dados, aliado a um projeto preservacionista, que reivindicava a necessidade de aprender métodos, e a ligação com uma corrente francesa que associava arqueologia à pré-história. Nesse vácuo institucional dos anos 30 aos 50 a arqueologia se descola das discussões sobre formação do estado nacional, sobre identidade e estuda uma pré-história descolado do presente - fatos do passado. Ao mesmo tempo, com a criação da SPHAN toda a questão sobre patrimônio é relegado ao Estado e fica nas mãos de historiadores e arquitetos. Essa situação geral acabou afastando a arqueologia das demais ciências sociais; ela não se associou às propostas estruturalistas apresentadas por Levy-Strauss enquanto este esteve no Departamento de Antropologia da USP, nem da escola dos annales, enquanto F. Braudel também esteve na USP, nem da corrente marxista da sociologia. ${ }^{31}$

Se esse período foi o de oficialização do ingresso da arqueologia na academia e de definição de uma pauta preservacionista, foi consequentemente também o período de formação de uma primeira geração de arqueólogos. Os postos da academia precisavam ser preenchidos e a legislação aplicada - ou seja a entrada da arqueologia na academia e a formação dos primeiros arqueólogos é resultado de uma damanda muito concreta - preservação. ${ }^{32}$

Durante as décadas de 1950 e 1960 esse processo de ingresso da Arqueologia na academia toma corpo e há uma série de iniciativas voltadas à formação dessa primeira geração de arqueólogos no Brasil. É no início da década de 1950, por exemplo, que a convite de Paul Rivet e Paulo Duarte (então à frente da Comissão de Pré-história de São Paulo), o arqueólogo francês Joseph Emperaire vem ao Brasil para trabalhar com sambaquis: sua primeira visita ocorre em 1954 e, no ano seguinte, retorna ao Brasil acompanhado por sua esposa - Annete Laming-Emperaire. Simultaneamente Jose. L. Fernandes inicia escavações no Paraná, as quais são continuadas por Oldemar Blasi em colaboração com W. Hurt, da University of Penilvânia. Ainda na década de 1950 o casal Betty Meggers e Clifford Evans realiza pesquisas na foz do amazonas e P.P. Hilbert escava sítios arqueológicos no médio Amazonas. Paralelamente a essas atividades, no Rio Grande do Sul Pedro I. Schmitz realiza pesquisas 
ao longo da década de 1950, sendo orientado pelo padre Balduino Rambo, o qual já pesquisava a arqueologia sul-riograndense desde a década de $1940 .{ }^{33}$

$\mathrm{Na}$ década seguinte as atividades se intensificam. No Rio de Janeiro, por exemplo, só durante esta década surgem 6 espaços distintos voltados para formação e discussão de aspectos relacionados à Arqueologia Brasileira: Associação Brasileira de Ensino e Pesquisas Arqueológicas, o Instituto de Arqueologia Brasileira, o Centro Brasileiro de Arqueologia, o Centro de Informação Arqueológica, a Faculdade de Arqueologia e o Instituto de Cultura Brasileira. Em 1962 surgem o laboratório de arqueologia da UFBA, coordenado por Valentin Calderón, o instituto de antropologia da UFRN, coordenado por Nássaro Nasser e o Instituto de Pré-História, em São Paulo.

O evento mais importante, mais emblemático da formação dos arqueólogos no Brasil são os cursos de extensão e seminários oferecidos no CEPA durante a década de 1960 . Vários pesquisadores nacionais e internacionais participaram como docentes nestes cursos: W. Hurt, A. LamingEmperaire, Oldemar Blasi, J.J. Bigarella, L. Castro Faria., P.P.Hilbert, B. Meggers, C. Evans. Esses cursos, organizados em forma de seminários, foram ministrados ao longo da década de sessenta e contaram com a participação de pesquisadores que vieram a compor a primeira geração de arqueólogos brasileiros formados no Brasil. Dentre eles podemos mencionar: Anamaria Beck, Braz Francisco Peppe, Celso Perota, Fernando Altenfelder, Igor Chmyz, João Alfredo Rohr, José Proença Brochado, Jose Rauth, Marcos Albuquerque, Margarida Andreatta, Maria da Conceição Beltrão, Maria Heloisa Fenelon, Maria José Menezes, Mário Simões, Nássaro Nasser, Ondemar Dias, Pedro Ignácio Schmitz, Valentin Calderón, Walter Piazza. Dentre os cursos, há alguns emblemáticos em função do resultado, da repercussão e do impacto que tiveram na consolidação da Arqueologia no Brasil: curso sobre métodos de campo e laboratório aplicados a sambaqui, ministrado por A. Lamming-Emperaire, seminário de ensino e pesquisas em sítios cerâmicos, coordenado por Betty Meggers e Clifford Evans e o seminário de ensino e pesquisa em sítios précerâmicos, coordenado por A. Lamming-Emperaire. ${ }^{34}$

Durante esse período há ainda uma série de outras iniciativas postas em prática no contexto nacional, evidenciando uma certa efervescência na arqueologia nesse momento. Assim, se entre as décadas de 1920 e 1950 há uma pulverização da arqueologia, com criação de centros regionais e sociedades locais, a disputa pelo estabelecimento de uma legislação capaz de garantir a preservação do patrimônio arqueológico é inevitavelmente acompanhada por uma discussção em torno de quem será capaz, responsável e autorizado a aplicar essa legislação. Com a lei 3.924 e a intervenção do SPHAN há um movimento para profissionalizar o exercício da atividade de arqueólogo. No entanto, essa profissionalização se confunde com academicização - o profissional é o 
acadêmico, só está apto a ser arqueólogo quem ocupa cargos na academia; ou seja, é a academia que confere legitimidade ao discurso. Dessa forma este é um momento crucial para arqueologia brasileira, quando se definem "os donos do discurso e do saber". ${ }^{35}$

Tendo em vista o contexto e a demanda específica que levou à estruturação desses cursos, vemos que sua orientação aponta para a valorização de um saber extremamente técnico; são principalmente questões relativas à métodos e técnicas que compõem o nucleo do conteudo discutido nesses cursos. Assim como aconteceu na institucionalização da Arqueologia no âmbito dos museus, nos anos 1950/60 o conhecimento necessário para aplicação da legislação girava em torno de metodos e tecnicas para registrar de forma rigorosa os dados oriundos das intervenções em curso. Mais uma vez era o domínio da técnica que distinguiria profissionais de amadores - a arqueologia se academiciza enquanto método, herdando portanto uma tradição que já vinha desde Império e principalmente República.

Essa aceitação e disseminação de arqueologia como método/técnica não é algo que deva ser imputado ao casal Meggers e Evans ou à herança francesa apenas e de forma direta, mas fruto de uma fusão, da interação entre propostas e tradição que envolvem questões de estruturação do poder interno, latentes no contexto sócio-político brasileiro e vinculadas à arqueologia que já se fazia no Brasil desde o começo do século XIX. ${ }^{36}$

Conforme mencionamos a lei 3.924 é formulada em um ambiente completamente diferente da lei de 1937, marcado por um período de abertura democrática, de consolidação das Universidades, de diversidade política. Além disso, temos que entender também o incremento da demanda pela preservação desse Patrimônio em sua articulação com o Projeto Desenvolvimentista de Juscelino Kubitschek, que anos antes é responsável pela construção de grandes obras de infra-estrutura no Brasil, causando certamente com isso um grande impacto ao Patrimônio Arqueológico Nacional.

Além dos já mencionados nomes de Luis de Castro Faria, então no Museu Nacional, Paulo Duarte na USP e José Loureiro Fernades, na UFPR é preciso mencionar outros dois nomes que, se não participaram da formulação das leis, atuaram na prática impedindo ou registrando a destruição de importantes sítios arqueológicos nesse período: Padre João Alfredo Rohr, com uma atuação importante na região central de Santa Catarina, especialmente em Florianopolis e Guilherme Tiburtius, cujos trabalhos resultaram na composição de um vasto e diversificado acervo de vestígios arqueológicos que fomentou a criação do Museu do Sambaqui, em Joinvile. ${ }^{37}$

Após 1961, há um longo interregno com relação às questões jurídicas direcionadas ao Patrimônio Arqueológico que será retomada apenas na Constituição de 1988. No entanto, apesar de não estar estritamente relacionada 
ao Patrimônio Arqueológico é importante mencionar a Resolução CONAMA 001/86 que define o que é, o que envolve e como deve transcorrer uma avaliação ambiental. ${ }^{38}$

\section{ESTABILIDADE ECONÔMICA E A NOVA INSTITUCIONALIZAÇÃO DA ARQUEOLOGIA: DEMANDA DO MERCADO}

Após a década de 1960 a Arqueologia Brasileira passa por um processo de consolidação em termos institucionais, jurídicos e acadêmicos. Cresce de forma continuada o número de arqueólogos formados em instituições de ensino superior no Brasil e também no exterior e cria-se uma Sociedade de Arqueologia Brasileira. ${ }^{39}$ Principalmente a partir de meados da década de 1980 há uma pluralidade de perspectivas teóricas e uma ampliação dos temas de pesquisa e abordagens metodológicas. É também neste momento que a Arqueologia Preventiva toma corpo, com os primeiros trabalhos e as primeiras empresas constituídas especificamente para prestar esse tipo de serviço surgindo no Brasil. $^{40}$

Acompanhando essa mudança, surgem novas conceituações sobre patrimônio que do ponto de vista legal aparecem representadas na Constituição Federal de 1988. Segundo consta na Constituição, Patrimônio Cultural inclui "bens de natureza material e imaterial, tomados individualmente ou em conjunto, portadores de referência à identidade, à ação, à memória dos diferentes grupos formadores da sociedade brasileira". Entre esses bens incluem-se "formas de expressão, modos de criar, fazer e viver, criações científicas, artísticas e tecnológicas, obras, objetos, documentos e edificações e conjuntos urbanos e sítios de valor histórico, paisagístico, artístico, arqueológico, paleontológico, ecológico e científico". ${ }^{41}$

De forma sintomática temos ainda no mesmo ano a promulgação da Portaria SPHAN 07/1988, regulamentando a concessão de licenças para realização de pesquisas arqueológicas em todo território nacional.

No entanto, do ponto de vista da formação, apesar do crescimento acadêmico da disciplina, entre 1960 e começo dos anos 2000 há apenas uma instituição de ensino superior no país que oferece um curso de graduação voltado à formação de arqueólogos. Grande parte dos profissionais atuando na área adquirem uma formação inicial em cursos de graduação vinculados à diferentes áreas, como História, Biologia, Geologia e Antropologia, complementando sua formação na pós-graduação.

Essa situação se altera de forma significativa a partir dos anos 2000 e pode ser entendida como resultado direto do crescimento e intensificação 
das atividade vinculadas à Arqueologia Preventiva. É já a partir de meados da década de 1990, com o começo da estabilidade econômica no Brasil que a atuação da Arqueologia Preventiva tende a crescer exponencialmente, atingindo níveis extraordinários a partir do ano 2000. Acompanhando essa trajetória, em meados da década de 1990 e começo dos anos 2000 surgem novos programas de pós-graduação, embora, ao mesmo tempo, feche o primeiro curso de graduação em Arqueologia do País. No entanto, a partir do ano 2004 surgem novos cursos de graduação em Arqueologia, totalizando, em 2011, dez cursos oferecidos em Instituições de Ensino Superior localizadas em todas as regiões do país.

Nesse sentido, julgamos ser possível falar em um novo marco no processo de institucionalização da Arqueologia no Brasil, representado por mudanças na prática arqueológica, na legislação e, principalmente na formação dos Arqueólogos no país.

Do ponto de vista jurídico um elemento fundamental associado ao crescimento da demanda por mão-de-obra qualificada para realização de trabalhos de cunho arqueológico é a Portaria IPHAN 230 de 2002, que procura correlacionar etapas do licenciamento aos trabalhos arqueológicos, definindo os requisitos necessários para implantação de cada etapa do empreendimento. É também só neste momento que a educação passa a ser um elemento obrigatório na execução dos trabalhos de Arqueologia, ampliando ainda mais o leque de atuação do Arqueólogo e seu compromisso para com um Patrimônio que tem importância hoje e que fala sobre as pessoas do presente.

Tendo em vista este contexto, a correlação entre Crescimento Econômico - Arqueologia Preventiva - Surgimento dos cursos de Graduação - é uma realidade inegável. Ou seja, esse novo marco da institucionalização da disciplina surge em função de uma demanda decorrente da arqueologia preventiva, de uma demanda de mercado..$^{42}$ Mais que isso, este marco surge impulsionado por duas vias diretamente ligadas à agenda política do governo federal: o desenvolvimentismo do PAC e o REUNI. ${ }^{43}$

Nesse sentido cabe-se perguntar qual o conteúdo e a orientação desses novos cursos. Segundo Bezerra ${ }^{44}$

As diferenças entre o currículo da Estácio de Sá, de 1981, e dos cursos de hoje apontam para a introdução de disciplinas tais como Arqueologia de Contrato, Administração Aplicada à Arqueologia, Legislação Ambiental, Preservação do Patrimônio, Educação Ambiental e Educação Patrimonial, que aparecem de uma forma ou de outra em todos os currículos. ...As principais inovações na maior parte dos currículos examinados voltam-se, especialmente, para as demandas dos projetos de desenvolvimento. E ao que tudo indica, há uma acentuação do seu aspecto técnico. 
Seguindo as inquietações de Bezerra, a autora se questiona a respeito do rumo desses novos cursos no sentido de criarem programas específicos de Arqueologia, sem se vincular à História ou à Antropologia. Isso pode ser visto como decorrente de um processo histórico no qual a Arqueologia, eminentemente descritiva, empiricista, classificatória, se distanciou nas discussões teóricas de ambas as disciplinas, assumindo um caminho particular, aproximando-a muito mais de uma técnica do que de uma disciplina acadêmica - essa técnica, por si só não era suficiente para legitimar a criação de um campo independente, mas sua associação a um perfil pragmático, a uma demanda de mercado, criou o espaço necessário para consolidar sua dissociação da História e da Antropologia. Assim, como demonstra a autora os cursos de graduação não apresentam em sua grade curricular nenhuma ou muito poucas disciplinas teóricas, sejam elas de arqueologia, antropologia ou história. ${ }^{45}$ Esta não é nem nunca foi uma preocupação para a Arqueologia Brasileira.

\section{PATRIMÔNIO ARQUEOLÓGICO, ACADEMIA E PÚBLICO}

Não só no ambiente acadêmico, é senso comum a constatação de uma ausência de identificação do povo, da população brasileira com o Patrimônio. Isso está diretamente relacionado a uma outra questão que envolve um não reconhecimento na história da nação, no ideário nacional, na memória construída desde os tempos do império. Segundo Chauí "índios são ignorantes, negros são indolentes, nordestinos são atrasados, portugueses são burros, mulheres são inferiores - mas nós somos todos orgulhosos de sermos brasileiros."

Ou seja, a imagem que se construiu do Brasil exclui ou descaracteriza a participação de uma série de agentes fazendo com que estes, apesar de veicularem esse discurso, não se reconheçam de fato no Patrimônio. ${ }^{47}$ Assim, ao invés de dizermos que os brasileiros não têm memória, o que vemos é que os brasileiros, de um modo geral, não participam da construção dessa memória. ${ }^{48}$ Por mais que ela seja veiculada, transmitida, re-transmitida e afirmada ela não é interiorizada, não é vivenciada, o que se reflete diretamente na relação que este público estabelece com o Patrimônio, a qual passa muitas vezes pelo não reconhecimento ou pela negação e até pela destruição.

Como dissemos no início do texto e vimos no item anterior a academia tem um papel importante nesse processo e, apesar da atuação ativa de Paulo Duarte, Luis de Castro Faria e José Loureiro Fernandes na década de 1950/60, podemos dizer que tanto patrimônio quanto educação permaneceram e de certa forma permanecem distantes das principais preocupações acadêmicas no âmbito da arqueologia. 
Enquanto o patrimônio foi de certa forma delegado à esfera jurídica, ficando sob responsabilidade de órgãos federais como a SPHAN, criada na década de 1930 e transformada em IPHAN na década de 1990, a educação a respeito de temas da arqueologia, principalmente nos ensino fundamental e médio, foi delegada a historiadores ou a não especialistas, amadores e curiosos em geral.

Esse distanciamente entre essas três esferas teve e continua tendo uma série de reflexos. A ausência de uma regulamentação da profissão é um exemplo disso já que há uma série de esferas de atuação do arqueólogo que são ocupadas e desempenhadas por diferentes tipos de profissionais, com formação e experiências bastante diversificadas. A ausência da Arqueologia no ensino médio ou mesmo em nível de graduação também é um exemplo disso. Nesse caso, não só o desinteresse, ou a falta de atuação dos arqueólogos na divulgação do conhecimento para esse público, mas a construção de uma memória que relega a história dos grupos indígenas no período anterior a conquista a uma préhistória estática e atrasada contrubuíram de forma significativa para ausência da arqueologia nos currículos escolares. Ainda outro reflexo disso está na forma como a população concebe o patrimônio e se relaciona com ele, o que muitas vezes envolve desconsideração, descaso frente às questões culturais em geral.

Esse afastamento da arqueologia acadêmica, no entanto não é fortuito, não é obra do acaso, não decorre de uma atitude ingênua. Segundo uma série de autores ${ }^{49}$ essa postura reflete uma posição política clara, embora nem sempre consciente sobre produção e circulação do poder através do discurso. Esses autores relacionam essa postura ao processo de institucionalização da Arqueologia no Brasil que esteve associado no Império e na República à políticas de colonialismo interno e dominação. Um paralelo dessa postura é visível na política indigenista que mesmo oscilando entre a defesa do extermínio ou da pacificação considera o índio como selvagem, de natureza indolente que, no primeiro caso não teria salvação, enquanto, no segundo, ainda poderia se tornar uma pessoa civilizada através de umprocesso educacional rigoroso. Essa postura permeia, por exemplo, todo o debate sobre origens naturais e artificiais dos sambaquis, o qual se perpetua praticamente até os anos 1950. Esse paralelo e esse exemplo, transmitem uma ideia sobre a visão, a concepção de passado que permeou a Arqueologia nesse seu processo de institucionalização e que certamente influenciou a concepção de Patrimônio. ${ }^{50}$

Nesse processo de institucionalização da Arqueologia há, no entanto, um momento em que esse distanciamento é de certa forma rompido e se procura uma inter-relação da Arqueologia com Patrimônio e Educação. Como dissemos é o momento de consolidação das universidades e o resultado dessa ação gera a lei 3924 de 1961, no que se refere ao Patrimônio e a elaboração e realização 
dos primeiros seminários, talvez o primeiro curso formal destinado à formação de arqueólogos no Brasil.

Apesar de uma atuação ainda tímida com relação ao Patrimônio, é essa primeira geração que começa a desenvolver trabalhos orientados para garantir a preservação do Patrimônio, principalmente através da Arqueologia de Contrato.

No entanto, essa tentativa de aproximação da Arqueologia com o Patrimônio e a Educação não acarreta de fato em uma mudança da relação que o público em geral estabelece com o Patrimônio. A arqueologia continua sendo vista como uma atividade exótica, um divertimento e, nesse contexto, o patrimônio é visto apenas como curiosidade..$^{51}$

Para reverter essa situação é preciso então mudar a forma como a própria arqueologia é vista, é preciso mostrar como a arqueologia pode ser um instrumento na construção da memória, da história, da identidade, da cidadania. O principal instrumento para isso é a educação. ${ }^{52}$

Essa postura, essa perspectiva começou a ganhar espaço a partir do incremento das atividades relacionadas à Arqueologia Preventiva, cuja sustentação legal foi incrementada a partir da Portaria SPHAN 07/88, mas principalmente com a promulgação da Portaria 230/02. É só neste momento que a educação assume um papel oficial, claro e necessário no âmbito dos trabalhos de arqueologia.

Construída dessa forma a relação entre Arqueologia-PatrimônioEducação, chegamos necessariamente às questões: para quem serve a arqueologia? Qual passado, qual memória queremos e vamos construir? A Arqueologia tem valorizado a diversidade cultural? Como a Arqueologia tem trabalhado com a questão da identidade, reforçando-a, negando-a?

Todas essas questões devem ser colocadas pela Arqueologia, pois são esses discursos que sustentam a noção de patrimônio enquanto a sua produção e veiculação envolve necessariamente a educação.

\section{CONCLUSÃO}

Ao longo desse texto procuramos reiterar e demonstrar que a Arqueologia é inevitavelmente uma ciência social e que seu processo de institucionalização está intimamente relacionado às transformações políticas e sociais pelas quais a sociedade brasileira passou, desde os primeiro tempos do Império. Com isso, é legítimo afirmar que a arqueologia envolve atores sociais que efetuam escolhas orientadas pelo papel que desempenham na sociedade, definidos por compromissos assumidos de forma às vezes mais às vezes menos conscientes. Nesse sentido a atuação na profissão envolve necessariamente questões éticas e responsabilidade perante à construção do discurso. Entre essas 
responsabilidades estão a construção, definição e preservação do patrimônio e a produção e divulgação do conhecimento para públicos variados.

Ao longo da História da Arqueologia no Brasil vemos vários momentos de intersecção entre esses aspectos. Mudanças na legislação e na conceituação de patrimônio caminham a par e passo com o processo de institucionalização da disciplina. Com as modificaçãoes da legislação referente ao Patrimônio decorrentes da promulgação da lei 3.924, surge um problem específico: demanda por mão-de-obra qualificada para aplicação dessa lei e garantia de preservação do Patrimônio. Nesse momento, a "solução" são os cursos do CEPA que resultam na entrada da Arqueologia na Academia. Em 2004 vemos acontecer um processo muito semelhante uma vez que é logo após a ediçao da Portaria IPHAN 230 de 2002 que a Arqueologia passa por um novo e intenso processo de institucionalização, com a criação de uma dezena de cursos de gradução. Ou seja, novamente o ingresso da Arqueologia na academia se deve a um pressão decorrente da necessidade de formação de uma mão-de-obra qualificada e capaz de lidar com os problemas decorrentes da intensificação do impacto e destruição causadas ao patrimônio arqueológico. Nos dois contextos, separados por quase 50 anos há vários elementos semelhantes, apontando para importância das discussões sobre proteção do patrimônio no processo de institucionalização da Arqueologia.

Assim a relação entre Arqueologia e Patrimônio é emblemática da constante inter-relação que existe entre Academia e Sociedade, seja esta constituída por congruências ou dissonâncias de interesse. Com isso podemos dizer que a Arqueologia desempenha, ou melhor, pode e deve desempenhar um papel fundamental na definição do que é patrimônio, devendo usar essa prerrogativa no intuito de democratizar a educação e promover a inclusão social. Ou seja, há uma relação intrínseca entre Arqueologia, Patrimônio e Educação e cabe a cada um assumir de forma consciente uma posição frente a essa questão.

\section{NOTAS}

1 ALMEIDA, M. B. O australopiteco corcunda. As crianças e a Arqueologia em um Projeto de Arqueologia Pública na Escola, 2002. Tese (Doutorado em Arqueologia) . Museu de Arqueologia e Etnologia, Universidade de São Paulo; BASTOS, R. Arqueologia Pública no Brasil: novos tempos. In Mori, V.H., Souza, M.C., Bastos, R. E Gallo, H. Patrimonio: atualizando o debate. São Paulo, IPHAN, 2007. Cap.5, p.157-167; FERREIRA, L. Território Primitivo: a institucionalização da arqueologia no Brasil (1870-1917). Porto Alegre, RS, EDIPUCRS, 2010; FUNARI, P.P. Public archaeology from a Latin American perspective. Public Archaeology, American Anthropological Association, v.1, n.4:239-243, 2001; Silva, F. Arqueologia e etnoarqueologia na aldeia Lalima e na Terra Indígena Kayabi: reflexões 
sobre arqueologia comunitária e gestão do Patrimônio Arqueológico. Revista do Museu de Arqueologia e Etnologia/USP, São Paulo, n.19:205-220, 2009.

2 HODDER, I. Reading the past: curent approaches to interpretation in archaeology. Cambridge, Cambridge University Press, 1986; SHANKS, M., TILLEY, C. Reconstructing Archaeology. Cambridge, Cambridge University Press, 1987; TILLEY, C. (ed.) Interpretative Archaeology. Cambridge, Cambridge University Press, 1993.

${ }^{3}$ FERREIRA, L. Vestígios de Civilização: O Instituto Histórico e Geográfico Brasileiro e a construção da Arqueologia Imperial (1838-1870). Revista de História Regional, v.4, n.1:936, 1999; BARRETO, C. A construção de um passado pré-colonial: uma breve história da Arqueologia no Brasil. Revista USP, São Paulo, n.44:32-51, 1999/2000.

${ }^{4}$ BARRETO, C., MACHADO, J. Exploring the Amazon, explaining the Unknown: views from the past. In Mcewan, C., Barreto, C. and Neves, E. Unknown Amazon. London, The British Museum Press, p.232-251, 2001; FERREIRA, L. Footsteps of the American Race. Archaeology, Ethnography, and Romanticism in Imperial Brazil (1838-1867). In Funari, P., Zarankin. A. e Stovel, E. Global Archaeological Theory. Contextual Voices and Contemporary Thoughts, New York, Boston, Dordrecht, London, Moscow, Kluwer Academic/Plenum Publishers, 2005, cap.19, 337-352.

5 BARRETO 1999/2000, FERREIRA 2010; SCHWARCZ, L. O Espetáculo das Raças. São Paulo, Companhia das Letras, 1993.

${ }^{6}$ BARRETO 1999/2000

7 MELATTI, J. A antropologia no Brasil: um roteiro. Brasília, Série Antropologia, 1983.

${ }^{8}$ BARRETO 1999/2000

9 BARRETO 1999/2000, SOUZA 1991

${ }^{10}$ SOUZA, A. História da Arqueologia Brasileira. Pesquisas-Antropologia, São Leopoldo, RS, n.46:1-140, 1991.

${ }^{11}$ PROUS, A., Arqueologia Brasileira. Brasilia, Editora UnB, 1991

${ }^{12}$ SOUZA 1991:94

${ }^{13}$ Funari 1994, SOUZA 1991

${ }^{14}$ LIMA, T.A., Arqueologia na construção da identidade nacional: uma disciplina no fio da Navalha. Canindé, Xingó, n.9:11-24, 2007.

${ }^{15}$ SILVA, G. A materialização da nação através do Patrimônio: o papel do SPHAN no regime estadonovista, 2010. 138 p. Dissertação (Mestrado em História) PUC/RS, Porto Alegre; SOUZA 1991; NAJJAR 2005;

${ }^{16}$ SOARES, I.V. Proteção Jurídica do Patrimônio Arqueológico no Brasil. Erechim, Ed. Habilis, 2007.

${ }^{17}$ SOUZA 1991

${ }^{18}$ FARIAS, L.C. Antropologia - escritos exumados -2. Niterói, EdUFF, 2000; SILVA 2010

${ }^{19}$ CECCON, R. Em busca de uma "Arqueologia Brasileira”. Universidade Federal do Paraná, décadas de 1950 a 1970, 2011. 171f. Dissertação (Mestrado em História) PUC/RS, Porto Alegre; Simão 2009, SOUZA 1991 
${ }^{20}$ ALCANTARA, A. Paulo Duarte entre sitios e trincheiras em defesa de sua dama - a pre-história, 2007. 298f. Dissertação (Mestrado em Arqueologia) Museu de Arqueologia e Etnologia, Universidade de São Paulo; BARRETO 1999-2000:41, CECCON 2011, FARIAS 2000, SOUZA 1991

${ }^{21}$ FARIA 2000

${ }^{22}$ CECCON 2011

${ }^{23}$ ALCANTARA 2007, SOUZA 1991

${ }^{24}$ CECCON 2011, SOUZA 1991

${ }^{25}$ SOUZA 1991

${ }^{26}$ SOUZA 1991

${ }^{27}$ MOURÃO, H. Patrimônio Arqueológico: um bem difuso, 2007. Tese (Doutorado em Arqueologia) - Museu de Arqueologia e Etnologia, Universidade de São Paulo; SOARES 2007

${ }^{28}$ SOUZA 1991

${ }^{29}$ BARRETO 1999/2000, SOUZA 1991

${ }^{30}$ CECCON 2011

${ }^{31}$ SOUZA 1991, BARRETO 1999/2000, Correa, M. Revista de Antropologia: 1953-2003. Uma revista para muitas histórias. Revista de Antropologia, São Paulo, v.46, n.2:369-381, 2003; FRANÇOSO, M. O Museu Paulista e a História da Antropologia no Brasil entre 1946 e 1956. Revista de Antropologia, São Paulo, v.48, n.2:585-612, 2005.

${ }^{32}$ BARRETO 1999/2000, SOUZA 1991

${ }^{33}$ SOUZA 1991

${ }^{34}$ CECCON 2011, SOUZA 1991

${ }^{35}$ SOUZA 1991

${ }^{36}$ NOELLI, F. E FERREIRA, L., A persistência da teoria da degeneração indígena e do colonialismo nos fundamentos da arqueologia brasileira. História, Ciência, Saúde Manguinhos, Rio de Janeiro, v. 14, n. 4, 2007.

${ }^{37}$ SOUZA 1991

${ }^{38}$ CALDARELLI, S., SANTOS, M.C. Arqueologia de contrato no Brasil. Revista da USP, São Paulo, n.44:52-731, 999/2000.

${ }^{39}$ SOUZA, S. M., GASPAR, M. A Sociedade de Arqueologia Brasileira - SAB: perspectivas da maioridade. Artigo publicado nos Anais do IX Congresso da Sociedade de Arqueologia Brasileira. Rio de Janeiro, CD-ROM, 2000.

${ }^{40}$ BARRETO 1999/2000, CALDARELI E SANTOS 1999/2000

${ }^{41}$ MOURÃO 2010

${ }^{42}$ SCHAAN, D. E BEZERRA, M. Construindo a arqueologia no Brasil: a trajetória da Sociedade de Arqueologia no Brasileira. Belém, G K Noronha, 2009

${ }^{43}$ BEZERRA, M. Bicho de nove cabeças: os cursos de graduação e a formação de arqueólogos 
no Brasil. Revista de Arqueologia, Belém, v.21, n.2:139-154, 2008.

${ }^{44}$ BEZERRA, M. 2008:150

${ }^{45}$ BEZERRA, M. 2008.

${ }^{46}$ CHAUÍ apud ALMEIDA 2002

${ }^{47}$ ABREU, R. Museus, Patrimônio e diferenças culturais. In Abreu, R., Chagas, M. e Santos, M. (org.) Museus, coleções e patrimônios: narativas polifônicas. Garamond Universitaria, p.115-125, 2007; ALMEIDA 2002

${ }^{48}$ ALMEIDA 2002

${ }^{49}$ FERREIRA 2005, 2010, FUNARI 2005; SEQUEIRA, A. Brazilian Archaeology. Indigenous Identity in the Early Decades of the Twentieth Century. In Funari, P., Zarankin. A. e Stovel, E. Global Archaeological Theory. Contextual Voices and Contemporary Thoughts. New York, Boston, Dordrecht, London, Moscow, Kluwer Academic/Plenum Publishers, 2005, cap.20, p.353-364.

${ }^{50}$ FERREIRA 1999, 2005, 2010

${ }^{51}$ ALMEIDA 2002

${ }^{52}$ ALMEIDA 2002 